\title{
Hepatobiliary scintigraphy in vasculitis of the gallbladder as a manifestation of polyarteritis nodosa: a case report Bjoern Kitzing*1, Sandra O'Toole ${ }^{2}$, Adrian Waugh1, Jane Clayton ${ }^{3}$, Neil McGill ${ }^{3}$ and Kevin C Allman ${ }^{1}$
}

Address: ${ }^{1}$ Department of PET and Nuclear Medicine, Royal Prince Alfred Hospital, Missenden Road, Sydney, New South Wales, Australia, 2Department of Anatomical Pathology, Royal Prince Alfred Hospital, Missenden Road, Sydney, New South Wales, Australia and ${ }^{3}$ Department of Rheumatology, Royal Prince Alfred Hospital, Missenden Road, Sydney, New South Wales, Australia

Email: Bjoern Kitzing* - bkitzing@gmail.com; Sandra O'Toole - sot@yahoo.com; Adrian Waugh - awaugh@gmail.com; Jane Clayton - jane_clayton@hotmail.com; Neil McGill - neil_mcgill@gmail.com; Kevin C Allman - allman@yahoo.com

* Corresponding author

Published: 10 December 2009

Cases Journal 2009, 2:9300 doi:10.1186/1757-1626-2-9300

This article is available from: http://www.casesjournal.com/content/2/I/9300

(c) 2009 Kitzing et al; licensee BioMed Central Ltd.

This is an Open Access article distributed under the terms of the Creative Commons Attribution License (http://creativecommons.org/licenses/by/2.0), which permits unrestricted use, distribution, and reproduction in any medium, provided the original work is properly cited.
Received: 30 November 2009

Accepted: 10 December 2009

\begin{abstract}
Introduction: Polyarteritis nodosa can on rare occasions manifest itself as vasculitis of the gallbladder. Patients typically present with right upper quadrant pain and are initially worked up for cholecystitis. The definitive diagnosis is then usually based on surgical and histopathological findings.

Case presentation: In this case a 23-year-old Caucasian female presented with a 3 week history of right upper quadrant pain and fevers.

Conclusion: The clinical pathway and imaging findings of a rare case of gallbladder vasculitis as a manifestation of polyarteritis nodosa are demonstrated.
\end{abstract}

\section{Introduction}

We present the clinical pathway of a rare case of gallbladder vasculitis secondary to polyarteritis nodosa. The clinical pathway demonstrates the importance of the clinical presentation and the use of medical imaging in confirming the diagnosis.

\section{Case presentation}

A 23-year-old Caucasian female presented with a 3 week history of right upper quadrant pain, fevers, bilateral ankle pain and swelling with an accompanying rash. Her past medical history consisted of a previous hospital admission 3 months earlier due to an acute inflammatory polyarthritis associated with fever. During that admission the patient had developed a maculopapular rash over the trunk and limbs. Skin biopsies of the right thigh were taken which showed leukocytoclastic vasculitis. Symptoms improved after commencement of prednisone and the patient was discharged.

When the patient represented she had an elevated C-reactive protein $168 \mathrm{mg} / \mathrm{L}$ (normal: <12), erythrocyte sedimentation rate $76 \mathrm{~mm} / \mathrm{hr} \quad(0-12)$ and alkaline phosphatase $162 \mathrm{U} / \mathrm{L}$ (30-130). All her other blood results were normal. Rheumatoid Factor, ANCA and HLA B27 were negative as were blood cultures and viral serologies. Hepatobiliary scintigraphy was requested to investigate hepatobiliary function (Figures 1,2). The study was performed with $220 \mathrm{MBq}(5.9 \mathrm{mCi}) \mathrm{Tc}-99 \mathrm{~m}$ disofenin. The vascular phase appeared normal. The parenchymal phase showed an enlarged left lobe of the liver. Bile production was normal with rapid appearance in the intrahe- 


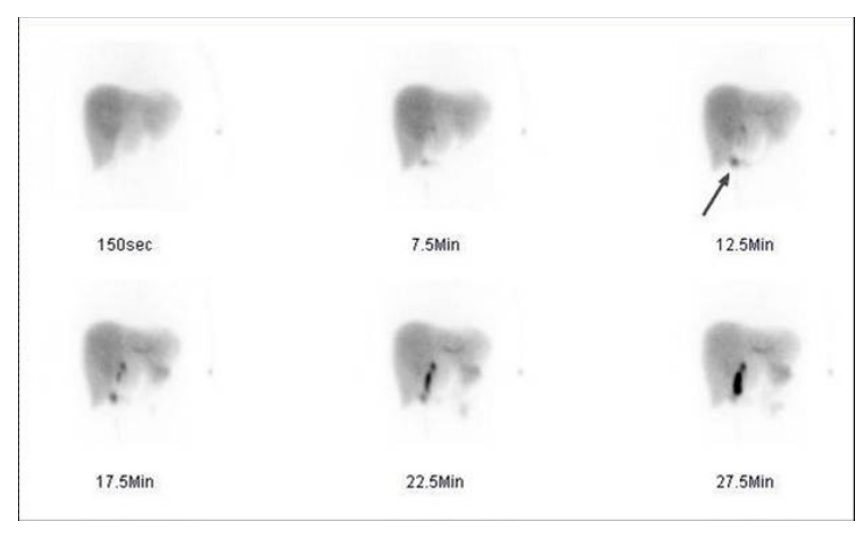

Figure I

Hepatobiliary scintigraphy of a 23-year-old white female with a three week history of right upper quadrant pain after injection of $220 \mathrm{MBq}(5.9 \mathrm{mCi}) \mathrm{Tc}-$ $99 \mathrm{~m}$ disofenin. Anterior dynamic views of hepatobiliary scintigraphy showing normal bile production with rapid appearance in the intrahepatic ducts and normal passage of bile into the bowel. A very small amount of activity entered the gallbladder early in the study (arrow).

patic ducts and normal passage of bile into the bowel. However, the gallbladder filled slowly during the study. An outpatient computed tomography scan which had been performed prior to admission showed a thickened gallbladder wall with surrounding fluid but no evidence of stones or duct dilatation (Figure 3).

Based on these findings and the clinical picture a laparoscopic cholecystectomy was performed. The postoperative recovery was unremarkable and the patient was discharged two days later and subsequently had no further right upper quadrant pain. Clinical follow-up one month later showed that she was still free of abdominal pain but had developed symptoms consistent with mononeuritis multiplex. Polyarteritis nodosa was considered the most likely diagnosis clinically.

Macroscopic examination of the gallbladder showed no gross abnormality. However, microscopic examination revealed a striking vasculitis affecting small to medium sized vessels, predominantly arteries. There was fibrinoid necrosis of many vessels associated with an inflammatory cell infiltrate, composed predominantly of lymphocytes with very occasional eosinophils (Figure 4). Almost every vessel in the histological sections was affected and some showed thrombotic occlusion. The findings were consistent with polyarteritis nodosa.

\section{Conclusion}

Polyarteritis nodosa (PAN) is an uncommon multisystem, necrotizing vasculitis of small- and medium-sized muscular arteries in which involvement of renal and vis-

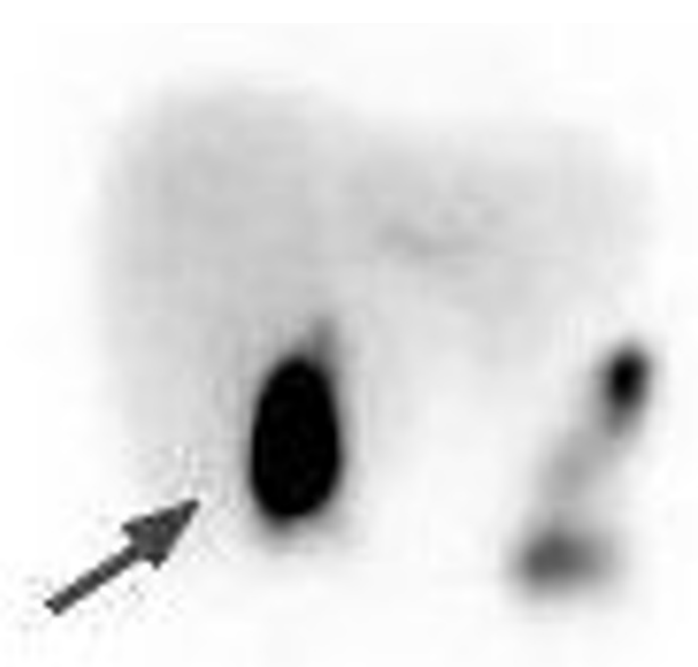

\subsection{Min}

Figure 2

Hepatobiliary scintigraphy of a 23-year-old white female with a three week history of right upper quadrant pain after injection of $220 \mathrm{MBq}(5.9 \mathrm{mCi}) \mathrm{Tc}$ $99 \mathrm{~m}$ disofenin. Anterior delayed static view of hepatobiliary scintigraphy demonstrating progressive build up of activity in the gallbladder (arrow) after 57.5 minutes.

ceral arteries is characteristic [1]. It was first described in its classic form by Kussmaul in 1866. The diagnosis of PAN is based on the demonstration of specific signs of vasculitis on biopsy material of involved organs as there are no diagnostic serologic tests. We present the hepatobiliary scintigraphy findings of a patient with cholecystitis which was a rare clinical manifestation of PAN.

Vasculitis is a clinicopathologic process characterized by inflammation of and damage to blood vessels. Polyarteritis nodosa (PAN) can cause specific complaints related to the vascular involvement within a particular organ system which may dominate the presenting clinical picture as well as the entire course of the illness. Involvement of the gastrointestinal tract has a $44 \%$ incidence in patients with classic PAN. Clinical manifestations include abdominal pain, nausea and vomiting, bleeding, bowel infarction and perforation, cholecystitis, as well as hepatic and pancreatic infarction. At autopsy $10 \%$ of patients with classic PAN have involvement of the gallbladder. 


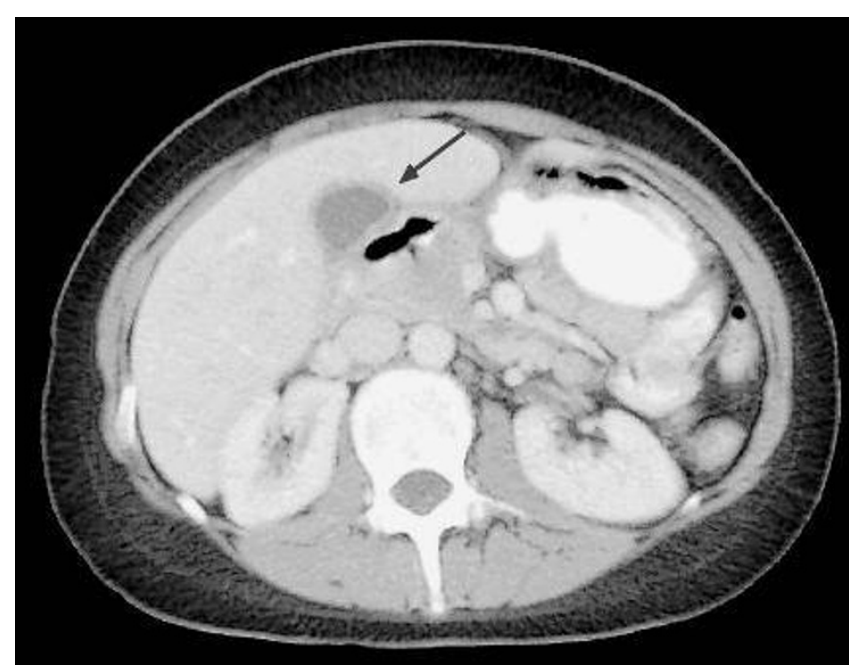

Figure 3

Select axial image of abdominal computed tomography of a 23-year-old white female with a three week history of right upper quadrant pain showing a thickened gallbladder wall (arrow) with surrounding fluid.

Gallbladder vasculitis of varying aetiology is rare but has been well described in the medical literature [2-13]. Abdominal pain, especially in the right upper quadrant is the most common presenting symptom. Liver function tests may be abnormal but as patients are usually thought to have cholecystitis secondary to cholelithiasis abdomi-

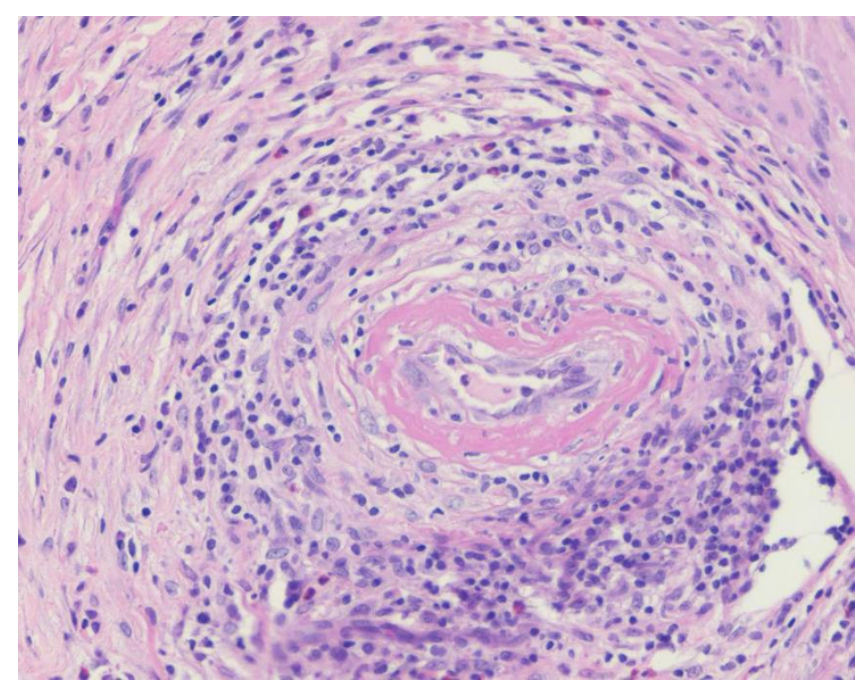

Figure 4

Histopathology of the gallbladder of a 23-year-old white female with a three week history of right upper quadrant pain showing fibrinoid necrosis of a small artery, associated with lymphocytes and macrophages infiltrating the wall. Occasional eosinophils are present. These findings are consistent with gallbladder vasculitis. nal ultrasound imaging is performed sometimes followed by computed tomography [14]. Following laparoscopic or open cholecystectomy the diagnosis is then made based on the intraoperative and histological evidence.

In this reported case the hepatobiliary scintigraphy findings were consistent with slow filling of the gallbladder most likely due to oedematous swelling of the vasculitic tissue as was subsequently demonstrated by the histopathology. Appropriate knowledge and awareness of gallbladder vasculitis secondary to polyarteritis nodosa will help interpret non-specific yet clearly abnormal hepatobiliary scintigraphy findings.

\section{Abbreviations}

ANCA: anti-neutrophil cytoplasmic antibody; HLA: human leukocyte antigen; PAN: polyarteritis nodosa; IDA: iminodiacetic acid.

\section{Consent}

Written informed consent was obtained from the patient for publication of this case report and all accompanying images. A copy of the written consent is available for review by the Editor-in-Chief of this journal.

\section{Competing interests}

The authors declare that they have no competing interests.

\section{Authors' contributions}

$\mathrm{BK}$, SOT and AW made substantial contributions to conception and design and drafted the manuscript. JC, NM and KCA revised it critically for important intellectual content and gave final approval of the version to be published.

\section{References}

I. Cupps TR, Fauci AS: The vasculitic syndromes. Adv Intern Med 1982, 27:315-344.

2. Juliano J, Wilson KD, Gertner E: Vasculitis of the gallbladder: case report and spectrum of disease. J Clin Rheumatol 2009, I 5:75-77.

3. Hashimoto A, Matsushita R, lizuka N, Kimura M, Matsui T, Tanaka S, Ishikawa $A$, Endo H, Hirohata S: Henoch-Schönlein pupura complicated by perforation of the gallbladder. Rheumatol Int 2009, 29:44I-443.

4. Ebert EC, Hagspiel KD, Nagar M, Schlesinger N: Gastrointestinal involvement in polyarteritis nodosa. Clin Gastroenterol Hepatol 2008, 6:960-966.

5. Fernandes SR, Samara AM, Magalhães EP, Sachetto Z, Metze K: Acute cholecystitis at initial presentation of polyarteritis nodosa. Clin Rheumatol 2005, 24:625-627.

6. Manoharan S, Muir J: Gallbladder vasculitis associated with cutaneous leucocytoclastic vasculitis. Australas J Dermatol 2004, 45:216-219.

7. Hoffmann JC, Cremer P, Preiss JC, Ebhardt H, Kruschewski M, Buhr $\mathrm{H}$, Zeitz M: Gallbladder involvement of Henoch-Schönlein purpura mimicking acute acalculous cholecystitis. Digestion 2004, 70:45-48.

8. Gorgun E, Ozmen V: Acalculous gangrenous cholecystitis in a young adult: a gastrointestinal manifestation of polyarteritis nodosa. Surg Laparosc Endosc Percutan Tech 2002, I2:359-36I. 
9. Rajvanshi P, Atac BS, Seno R, Gupta S: Gallbladder vasculitis associated with type-I cryoglobulinemia. Dig Dis Sci 200I, 46:296-300.

10. Chen KT: Gallbladder vasculitis. J Clin Gastroenterol 1989, I I:537-40.

II. Kumar B, Krishnani N, Misra R, Pandey R: Isolated necrotizing vasculitis of gallbladder: a report of two cases and review of literature. Indian J Pathol Microbiol 2003, 46:429-3I.

12. Burke AP, Sobin LH, Virmani R: Localized vasculitis of the gastrointestinal tract. Am J Surg Pathol 1995, 19:338-349.

13. Fish DE, Evans DJ, Pusey CD: Gallbladder vasculitis: a report of two cases. Histopathology 1993, 23:584-585.

14. Ha HK, Lee SH, Rha SE, Kim JH, Byun JY, Lim HK, Chung JW, Kim JG Kim PN, Lee MG, Auh YH: Radiologic features of vasculitis involving the gastrointestinal tract. Radiographics 2000, 20:779-794.

Publish with Bio Med Central and every scientist can read your work free of charge

"BioMed Central will be the most significant development for disseminating the results of biomedical research in our lifetime. "

Sir Paul Nurse, Cancer Research UK

Your research papers will be:

- available free of charge to the entire biomedical community

- peer reviewed and published immediately upon acceptance

- cited in PubMed and archived on PubMed Central

- yours - you keep the copyright

Submit your manuscript here:

http://www.biomedcentral.com/info/publishing_adv.asp 